\title{
Article \\ Semiochemical-Based Attractant for the Ambrosia Pinhole Borer Euplatypus parallelus
}

\author{
Hugo L. Rainho*D, Weliton D. Silva $(D)$ and José Maurício S. Bento \\ Department of Entomology and Acarology, University of São Paulo, Piracicaba, SP 13418900, Brazil; \\ wdsilv@gmail.com (W.D.S.); jmsbento@usp.br (J.M.S.B.) \\ * Correspondence: hugo.lleoncini@gmail.com
}

Citation: Rainho, H.L.; Silva, W.D. Bento, J.M.S. Semiochemical-Based Attractant for the Ambrosia Pinhole Borer Euplatypus parallelus. Agronomy 2021, 11, 266. https://doi.org/ 10.3390 /agronomy11020266

Academic Editors: Patrick Pageat and Andrea Liliana Clavijo McCormick Received: 21 December 2020

Accepted: 27 January 2021

Published: 31 January 2021

Publisher's Note: MDPI stays neutral with regard to jurisdictional claims in published maps and institutional affiliations.

Copyright: (c) 2021 by the authors. Licensee MDPI, Basel, Switzerland. This article is an open access article distributed under the terms and conditions of the Creative Commons Attribution (CC BY) license (https:// creativecommons.org/licenses/by/ $4.0 /)$.

\begin{abstract}
A semiochemical-based attractant for Euplatypus parallelus was identified and field-tested Analyses of headspace volatile extracts of conspecific males revealed the presence of 1-hexanol along with lesser amounts of 3-methyl-1-butanol, hexyl acetate, 1-octanol and trans-geraniol, which were not found in equivalent extracts from females. Emission of 1-hexanol coincided with the emergence of adults of both sexes during afternoon hours. A synthetic blend of these compounds, with and without ethanol, was tested in the field. The blend alone attracted a small number of females and no males. Ethanol alone attracted a small number of females (not significantly different from the blend alone) but significantly more males than the blend alone. More females were caught with the blend combined with ethanol than the combined catch of either attractant alone, suggesting a synergistic interaction. Attraction of males appeared to be a response to ethanol alone. During the trials, two potential natural enemies of E. parallelus were caught, indicating that they might be eavesdropping on the semiochemical channels of their prey. Traps containing the male-specific volatile compounds combined with ethanol could be applied as an effective attractant for detection and monitoring of E. parallelus as well as for recruitment of its natural enemies.
\end{abstract}

Keywords: ambrosia beetle; chemical ecology; pheromone; traps; quarantine species; monitoring; Platypodinae; Bothrideridae

\section{Introduction}

The Neotropical ambrosia pinhole borer, Euplatypus parallelus (Fabricius) (Coleoptera: Curculionidae: Platypodinae), is one of the most important invasive forest pests worldwide, causing damage in natural and managed forests in over 50 countries [1-3]. This beetle is highly polyphagous, attacking conifers and broadleaf trees of over 80 species from 25 botanical families [2-4]. Adult E. parallelus damage trees by boring deep galleries into the wood, inside of which they inoculate fungal symbionts that create a substrate for their larvae to feed [2,5]. In addition to the damage by the beetles, staining of the woody tissues by the associated fungi compromises the wood quality specially for furniture and veneer production $[2,6]$.

Outbreaks of E. parallelus are commonly associated with massive attacks on trees stressed by biotic or abiotic factors, such as damage by other insects, phytopathogens, storms, drought, fire, and forestry management practices [2,7-14]. The attacks compromise the physiology of trees, making them vulnerable to infection by phytopathogens that may result in high mortality in tree stands [7-9,12]. In Brazil, outbreaks of E. parallelus have been reported in commercial plantations of Pinus [10], Eucalyptus [11], Hevea brasiliensis (Willd. ex A.Juss.) Müll.Arg. [15], and Khaya senegalensis (Desv.) A.Juss. (present study, see Supplementary Material).

Attraction of adult platypodine beetles to stressed trees is mediated by volatile organic compounds (VOCs) [16,17]. Ethanol is released in large amounts by stressed trees [18-20], and platypodine beetles use this VOC as a chemical cue to locate their host [21,22]. In this 
case, adult males appear to locate and initiate colonization of a suitable host tree. After initiating a gallery, males emit a pheromone to attract conspecific females for mating and reproduction [5].

To our knowledge, male-produced attractant pheromones in platypodine beetles have been identified for five species: Megaplatypus mutatus (Chapuis) [23,24], Myoplatypus flavicornis (Fabricius) [25], Platypus cylindrus (Fabricius) [26], Platypus koryoensis (Murayama) [27], and Platypus quercivorus (Murayama) [28]. The pheromone of E. parallelus has not hitherto been addressed. Despite evidence of attraction of adult E. parallelus to ethanol-baited traps [29], there is no further information, either on the efficacy of this alcohol compared to other attractants or controls or on the sex ratio of attracted beetles.

Traps containing semiochemical blends (e.g., pheromones and kairomones) have been applied with success in surveillance programs for native and exotic forest pests [30]. Our objective was to identify a semiochemical-based attractant for E. parallelus that could be incorporated into traps for early detection or delineation of the geographical spread of this invasive species.

\section{Materials and Methods}

\subsection{Source of Chemicals}

The authentic standards 3-methyl-1-butanol (purity $\geq 99 \%$, CAS No. 123-51-3), 1hexanol $(\geq 99 \%, 111-27-3)$, hexyl acetate (99\%, 142-92-7), 1-octanol ( $\geq 99 \%, 111-87-5)$, and trans-3,6-dimethyl-2,6-octadien-1-ol (geraniol; 98\%, 106-24-1) were purchased from SigmaAldrich (Darmstadt, Hessen, Germany).

\subsection{Source of Beetles}

Adult males and females of E. parallelus were obtained from infested trees of African mahogany, Khaya senegalensis (Desv.) A. Juss. (Meliaceae), from a 15-year-old plantation ( $\sim 0$ ha) located in the city of Inocência, in the Brazilian state of Mato Grosso do Sul $\left(19^{\circ} 13^{\prime} 19^{\prime \prime} \mathrm{S} 52^{\circ} 09^{\prime} 31^{\prime \prime} \mathrm{W}\right)$ on 30 October 2017 . This plantation suffered a serious outbreak of E. parallelus in that year, which resulted in the typical symptoms of dieback wilt syndrome in many trees (Figure S1; Supplementary Material). Infested trees were sawn into logs (50 cm long $\times 25 \mathrm{~cm}$ diameter) and sent by courier to the Laboratory of Chemical Ecology and Insect Behavior, University of São Paulo, Piracicaba, SP ( $\sim 800 \mathrm{~km}$ from Inocência). The logs were housed in two black plastic containers $(89 \mathrm{~cm}$ long $\times 56 \mathrm{~cm}$ width $\times 48.5 \mathrm{~cm}$ height), and each container received three logs. Because adults of E. parallelus are positively phototactic, the newly emerged beetles were recovered from translucent bottles attached to the bottoms of the containers. The material was kept in a greenhouse with no control of environmental temperature and humidity. One of the containers was serviced daily from 16:00 to 18:00 $\mathrm{h}$ and the emerged beetles were used for headspace volatile collections. To determine the circadian rhythm of emergence of E. parallelus, the other container was checked for emerged beetles every two hours from 06:00-20:00 $\mathrm{h}$ and once from 20:0006:00 h over 19 days in November 2017.

In the laboratory, adults of E. parallelus were separated by sex under a stereomicroscope, based on morphological features described by Thube et al. [31]. Males have prominent spinelike projections on the declivity of the elytra, the striae of elytra are deeply impressed, and the body length is slightly shorter than that of females, whereas females lack elytral projections and impressed striae. Beetles were placed in groups of 10-20 individuals of the same sex in $50 \mathrm{~mL}$ Falcon tubes containing paper strips for perching and kept under controlled environmental conditions $\left(25 \pm 2{ }^{\circ} \mathrm{C}, 60 \pm 10 \% \mathrm{RH}, 12: 12 \mathrm{~L}: \mathrm{D}\right.$ and 5000 lux) $20 \mathrm{~h}$ prior to the headspace volatile collections.

\subsection{Collection of Beetle-Produced Volatile Compounds}

Headspace volatiles were collected from groups of 10-75 beetles (2-3 days old) of the same sex in cylindrical glass $500-\mathrm{mL}$ chambers. The inner surfaces of the chambers were lined with paper towels to provide a surface for perching. Volatiles were collected in 
glass pipettes ( $8.5 \mathrm{~cm}$ long $\times 0.5 \mathrm{~cm}$ i.d.) containing $150 \mathrm{mg}$ of $80 / 100$ mesh HayeSep ${ }^{\circledR} \mathrm{Q}$ adsorbent (Supelco, Bellefonte, PA, USA) held in place with glass wool plugs. Collectors were connected to outlets of chambers with screw caps fitted with PTFE ferrules. Activatedcharcoal-filtered air was pushed through the chamber at constant flow of $\sim 150 \mathrm{~mL} / \mathrm{min}$. Groups of beetles were continuously aerated for $48 \mathrm{~h}$ and then discarded. Chambers containing only paper towels were aerated in parallel to monitor system contaminants. Volatiles were eluted from collectors with three successive aliquots of $500 \mu \mathrm{L}$ of doubledistilled hexane into $2-\mathrm{mL}$ silanized amber glass vials, which were stored at $-30{ }^{\circ} \mathrm{C}$. Nine aeration extracts were obtained from each sex. The resulting extracts were not concentrated for the analyses.

\subsection{Identification of Beetle-Produced Volatile Compounds}

Headspace volatile extracts were initially analyzed using gas chromatography with flame ionization detection (GC-FID) to track sex-specific compounds, i.e., the potential attractant pheromone candidates. Two-microliter aliquots were injected into a GC-2010 gas chromatograph (Shimadzu Corp., Kyoto, Japan) fitted with a Rtx-1 capillary column (30 m $\times 0.25 \mathrm{~mm}$ i.d. $\times 0.25 \mu \mathrm{m}$ film; Restek, Bellefonte, PA, USA). Injections were made splitless (purge valve off for $1 \mathrm{~min}$ ) with injector port set at $250{ }^{\circ} \mathrm{C}$ and helium carrier gas at a linear velocity of $30 \mathrm{~cm} / \mathrm{s}$. The GC oven was programmed at $35^{\circ} \mathrm{C}$ (held $1 \mathrm{~min}$ ), increased to $40{ }^{\circ} \mathrm{C}$ at $2{ }^{\circ} \mathrm{C} / \mathrm{min}$ (held $1 \mathrm{~min}$ ), and then increased to $250{ }^{\circ} \mathrm{C}$ at $10^{\circ} \mathrm{C} / \mathrm{min}$ (held $10 \mathrm{~min}$ ).

Extracts containing compounds collected from adult males of $E$. parallelus were analyzed using gas chromatography-mass spectrometry with a Shimadzu QP2010 Ultra GCMS (Shimadzu Corp., Kyoto, Japan) fitted with a Rtx-1MS nonpolar column $(30 \mathrm{~m} \times 0.25 \mathrm{~mm}$ $\times 25 \mu \mathrm{m}$ film; Restek, Bellefonte, PA, USA). One microliter was injected splitless with an injector and GC oven temperatures were set as described above with helium carrier gas at $44 \mathrm{~cm} / \mathrm{s}$ and $80.8 \mathrm{kPa}$ inlet pressure. Ion source and quadrupole were set at $250^{\circ} \mathrm{C}$. Mass spectra were recorded in electron impact mode $(70 \mathrm{eV})$ from $\mathrm{m} / z$ 35-260 amu, with 4-min solvent delay. The candidate pheromone compounds were identified by retention indexes and mass spectra similarity with Library NIST 11 and confirmed by co-injection with authentic synthetic standards. Retention indexes were calculated by comparison with a blend of $\mathrm{C}_{5}-\mathrm{C}_{30}$ straight-chain alkane standards (Sigma-Aldrich, Darmstadt, Hessen, Germany).

\subsection{Emission of the Major Male-Specific Volatile Compound Over Time}

We ran an extra set of aerations of adult males of E. parallelus to determine the time of emission of the major sex-specific volatile compound. Groups of 12 adult males $(n=6$ replicate groups) were aerated from 06:00 to 22:00 $\mathrm{h}$ and volatiles were eluted from collectors at every 4-h interval. Elutions were done with two successive aliquots of $150 \mu \mathrm{L}$ of double-distilled hexane spiked with $1 \mathrm{ng} / \mu \mathrm{L}$ of nonyl acetate as internal standard. Because 1-hexanol was the major and most frequent component in male-specific volatile extracts (see Results), the quantifications were made on this compound. The results were expressed as nanograms of 1-hexanol per male per 4-h interval.

\subsection{Field Bioassay of Synthetic Male-Specific Volatile Compounds}

The synthetic blend of male-specific volatile compounds of E. parallelus (see Results) were field-tested in the same African mahogany plantation in Inocência (see above) from 13 October 2018 to 1 November 2018. We used custom-made cross-vane traps (translucent polyethylene terephthalate glycol panels; $24 \mathrm{~cm}$ high $\times 19.5 \mathrm{~cm}$ width). Translucent traps have shown excellent results for capture of other platypodine beetles-for example, M. mutatus in South America [32]. Collection jars (500 mL) were attached to the trap basins and filled with $250 \mathrm{~mL}$ of an aqueous solution of polypropylene glycol (20\%) to kill and preserve the captured beetles. Traps were suspended from inverted L-shaped hangers of PVC pipe $(1.8 \mathrm{~m} \times 2.5 \mathrm{~cm}$ i.d.), which were mounted on $1-\mathrm{m}$ reinforcing steel bars hammered halfway into the ground, so the trap base was at $\sim 1.2 \mathrm{~m}$ high. Lures consisted of clear polyethylene press-seal sachets $(5 \mathrm{~cm}$ width $\times 7 \mathrm{~cm}$ height, $80 \mu \mathrm{m}$ wall thickness, 
Daiso Ind. Co., Hiroshima, Japan) containing a roll of dental cotton loaded with 1-mL solution of a blend of male-produced volatiles in isopropanol. Lures were hung in the central open slot of the traps with pieces of plastic-coated wire.

The amount of each compound used per lure was based on the natural proportion emitted by adult males (see Results). The release ratio of the major component was similar to those described in previous studies with other platypodine species (i.e., $\sim 28 \mathrm{mg}$ /day) [32-34]. Because it was proved that adult E. parallelus are attracted to ethanol [29], we included a treatment lure composed of a 30-mL polyethylene flask filled with $99.5 \%$ ethanol. The flask was fitted with a $7-\mathrm{cm}$-long cotton-string wick to provide a high ethanol release rate $(\sim 2 \mathrm{~g} /$ day $)$, which is necessary to trigger the attraction of ambrosia beetle species [21,35]. Thus, the field bioassay comprised the following treatments: (1) MSV (male-specific volatiles) = blend of 3-methyl-1-butanol (1.5 mg), 1-hexanol (50 mg), hexyl acetate (2 mg), 1-octanol (3 mg), and geraniol (0.5 mg); (2) ethanol (EtOH; $20 \mathrm{~mL})$; (3) MSV $+\mathrm{EtOH}$; and (4) control (1 mL of neat isopropanol). Isopropanol was chosen because we have used it as a standard solvent for coleopteran pheromones [36] and it appears not to affect the attraction of beetles at the concentrations used here.

Treatments were assigned randomly to traps in five blocks, and each block contained one trap for each treatment. Traps were placed $30 \mathrm{~m}$ apart and blocks were spaced $50 \mathrm{~m}$ from each other. Traps were checked daily for captured beetles, at which time treatments were changed one position within blocks to control for positional effects. MSV lures were replaced every two days to prevent complete depletion of the minor components, and flasks were refilled with ethanol when the volume was depleted by $50 \%$.

Captured beetles were kept in Falcon tubes filled with $70 \%$ ethanol until identification in the laboratory. Beetles were collected under ICMBio permit \#60705-2, issued by the Brazilian Ministry of the Environment. Voucher specimens of E. parallelus were deposited in the "Luiz de Queiroz" Museum of Entomology, Department of Entomology and Acarology (USP/ESALQ), Piracicaba, SP, Brazil, under register codes ESALQENT000053 to ESALQENT000062.

\subsection{Statistical Analysis}

Differences between treatment means in the number of beetles caught were tested individually for species (represented by at least 10 specimens), using the nonparametric Friedman's test (PROC FREQ, option $\mathrm{cmH}$ ) [37] because the assumptions of ANOVA were violated by heteroscedasticity [38]. Replicates were considered as a block and collection date and replicates with zero captures (due, for example, to inclement weather) were omitted from the analysis. In recognition of the multiple statistical tests of treatment effects, significance level was adjusted by the number of species included in the analyses (i.e., $\alpha=0.017, n=3$ independent analyses), according to the Bonferroni procedure [39]. Pairs of means were compared using the Ryan-Einot-Gabriel-Welsch $Q$ multiple range test, which controls the Type I experimentwise error rate [37]. The sex ratio of adult E. parallelus emerged from African mahogany logs and caught with traps baited with the optimal attractant was compared to a nominal ratio of 0.5 with $95 \%$ Clopper-Pearson exact confidence intervals at $5 \%$ probability [40].

\section{Results}

\subsection{Identification of Beetle-Produced Volatile Compounds}

Headspace volatile extracts of adult males of E. parallelus showed five peaks that were absent from equivalent extracts of conspecific females (Figure 1) and controls. Their identities corresponded to the following compounds: 3-methyl-1-butanol (Retention Index on Rtx-1 column = 702), 1-hexanol ( $R I=820)$, hexyl acetate $(R I=996)$, 1-octanol (RI = 1055), and geraniol $(\mathrm{RI}=1233)$, which were produced by beetles in ratios (mean $\pm \mathrm{SD}, n=3$ aeration extracts) of $2.6 \pm 0.3: 100: 2.9 \pm 0.5: 4.3 \pm 2.2: 1.6 \pm 0.8$, respectively. Only 1-hexanol and hexyl acetate were found in $100 \%$ of male extracts; all other male-specific compounds were found in $75 \%$ of the extracts. 


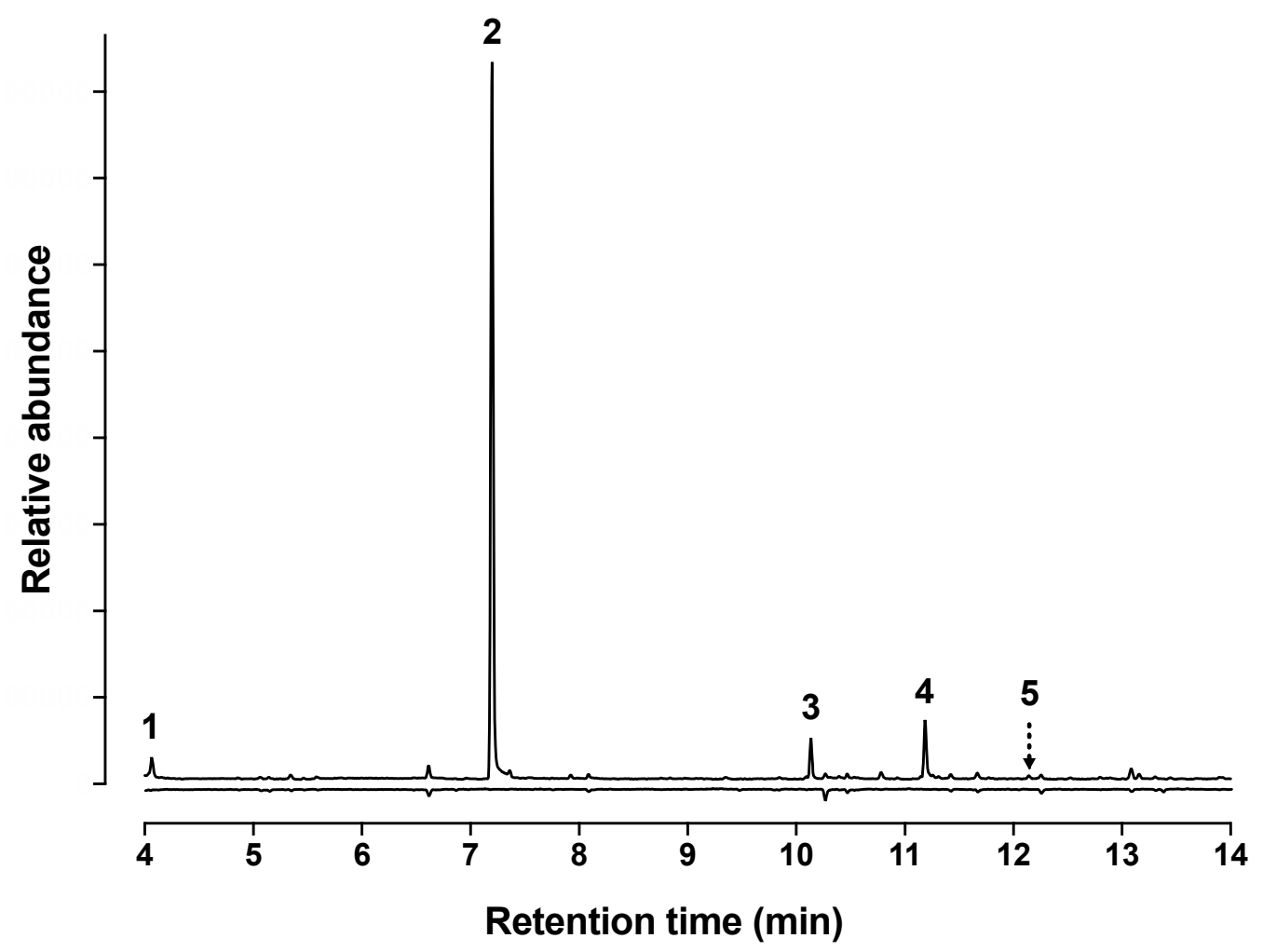

Figure 1. Representative total ion chromatograms of headspace volatile extracts from adult males (top trace) and females (bottom, inverted trace) of Euplatypus parallelus. Numbers on peaks represent the male-specific volatile compounds: 1 = 3-methyl-1-butanol; 2 = 1-hexanol; 3 = hexyl acetate; 4 = 1-octanol; and 5 = geraniol.

\subsection{Circadian Rhythm of Adult Emergence}

A total of 191 female and 200 male adults of E. parallelus emerged from mahogany logs during 19 days of evaluation. The sex ratio of emerged beetles did not differ significantly from an expected ratio of 0.5 (48.9\% females; Clopper-Pearson exact confidence intervals: $0.438-0.4539, p=0.649$ ). Emergences began in early afternoon with adult males, but a prominent peak of emergence including both sexes occurred between 14:00 and 18:00 $\mathrm{h}$. After that time, emergences declined dramatically. No beetles emerged from 20:00 $\mathrm{h}$ until next afternoon (Figure 2).

A total of 46 adults of Sosylus cf. cursorius (Pascoe) and Sosylus squirei (Pascoe) (Coleoptera: Bothrideridae) emerged from African mahogany logs during the 19-day collection.

\subsection{Emission of the Major Male-Specific Volatile Compound Over Time}

1-Hexanol was emitted by adult males of E. parallelus in all time intervals evaluated. Peak emission occurred from 14:00 to 18:00 h (Figure 3), corresponding with peak adult emergence (see above). 


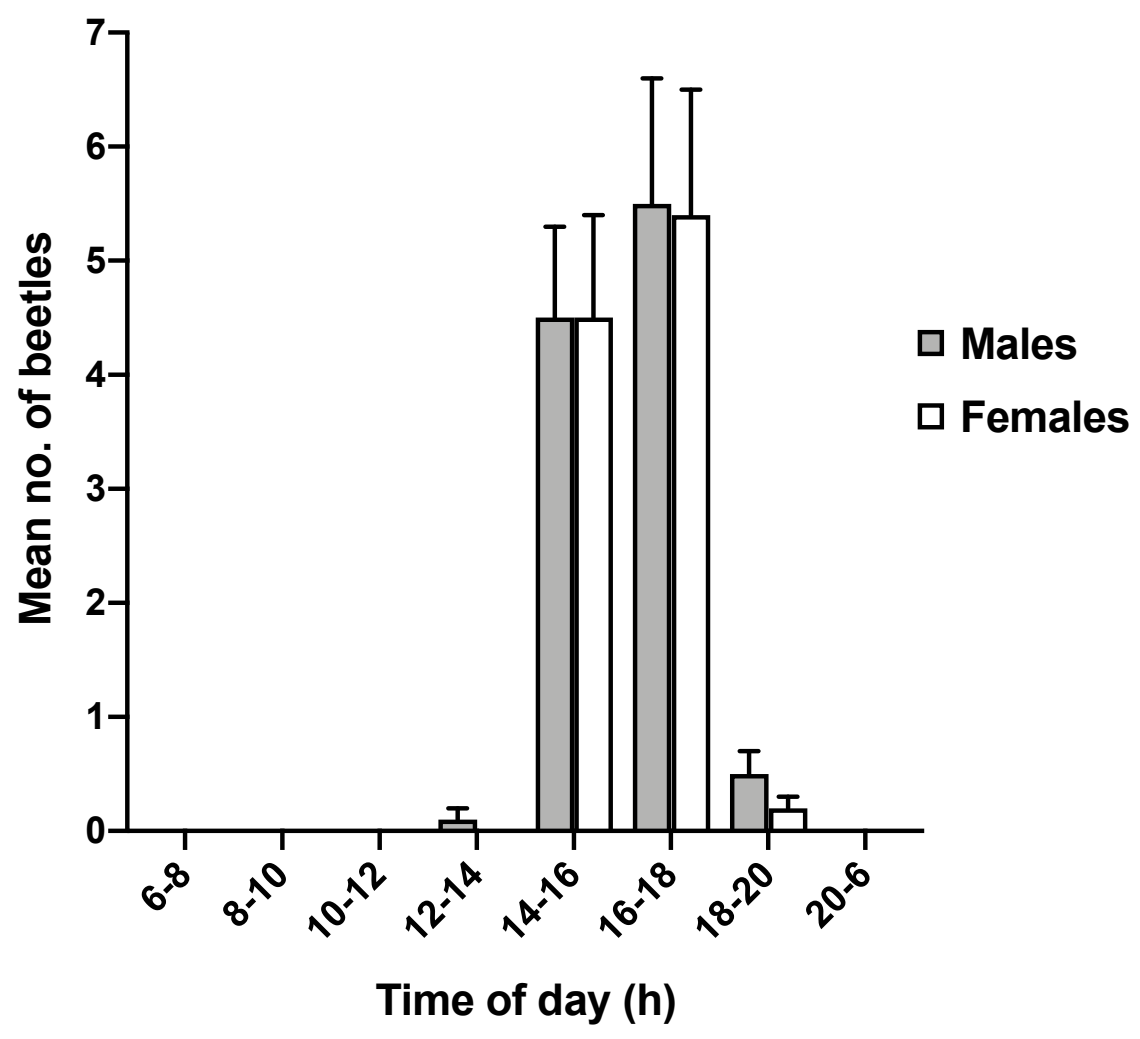

Figure 2. Mean ( \pm SE) numbers of adult females and males of Euplatypus parallelus emerged from logs of Khaya senegalensis over different times of day during 19 days of evaluation.

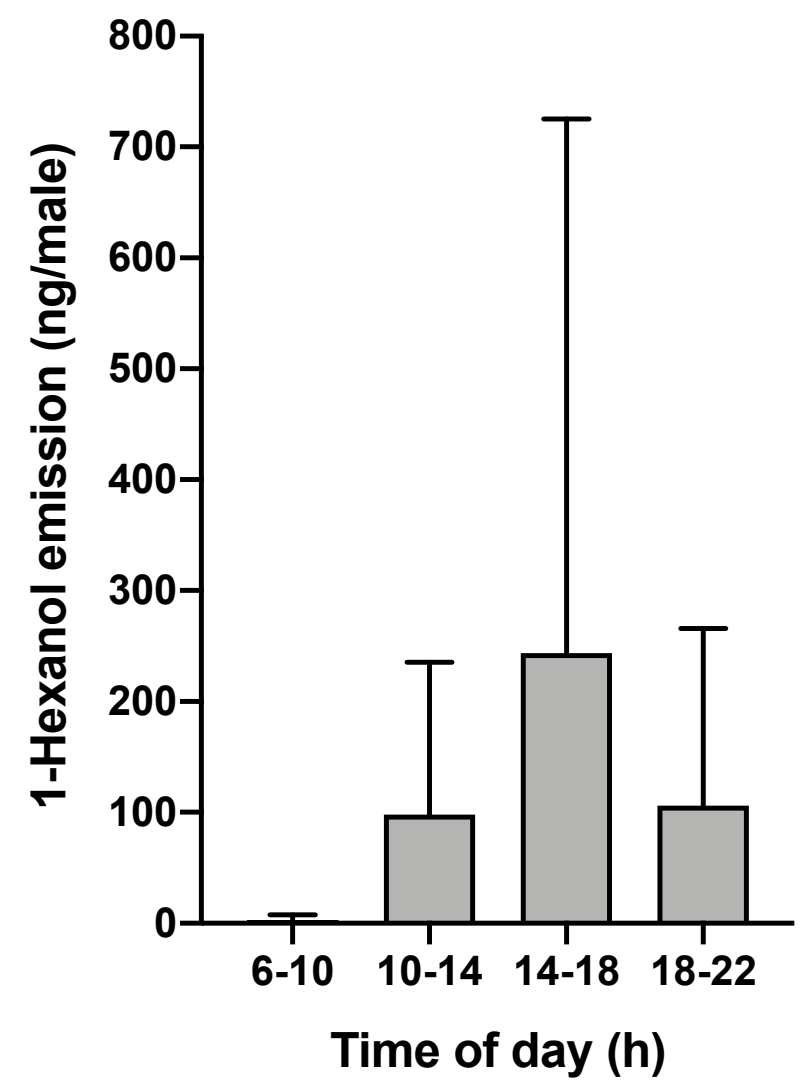

Figure 3. Mean $( \pm S D)$ amount of 1-hexanol emitted per male of Euplatypus parallelus in every 4-h interval from 06:00-22:00 h. 


\subsection{Field Bioassay of Synthetic Male-Specific Volatile Compounds}

Overall, 302 adult E. parallelus (194 males and 108 females) were caught during the field bioassay to test the reconstructed blend of male-specific volatile compounds. Adult females were significantly attracted to traps containing the combination male-specific volatiles (MSV) + ethanol (mean \pm SE of $1.7 \pm 0.2$ beetles/replicate) (Figure 4). A small number of females, not significantly different from zero, were collected in traps containing the MSV alone or ethanol alone. Adult males were attracted equally to the MSV + ethanol $(1.9 \pm 0.3)$ and ethanol alone $(1.2 \pm 0.3)$. No males were captured in traps baited with the MSV in the absence of ethanol (Figure 4). The sex ratio of beetles caught with the MSV + ethanol was male-biased ( $42.4 \%$ females; Clopper-Pearson exact confidence intervals: $0.355-0.495, p=0.029$ ). No other platypodine species was captured during the bioassay.

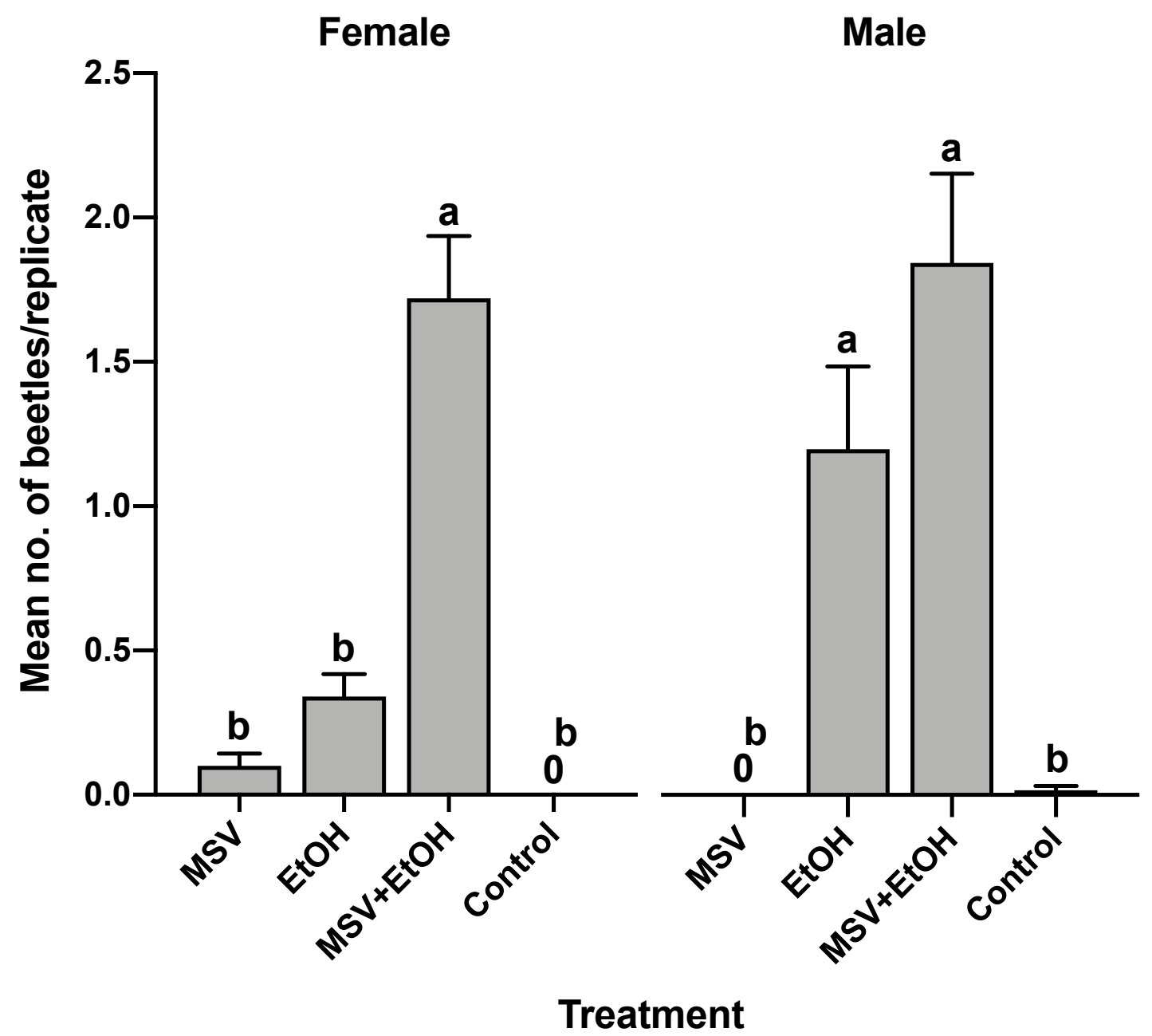

Figure 4. Mean $( \pm \mathrm{SE})$ numbers of adult females and males of Euplatypus parallelus caught with traps containing synthetic male-specific volatile compounds in combination or not with ethanol. Treatment abbreviations: MSV = male-specific volatiles, i.e., blend of 3-methyl-1-butanol, 1-hexanol, hexyl acetate, 1-octanol, and geraniol in the same ratio produced by conspecific males; $\mathrm{EtOH}=99.5 \%$ ethanol; control = neat isopropanol. Type of attractant lure significantly affected the trap catch of females $\left(Q_{3,200}=101.4, p<0.0001\right)$ and males $\left(Q_{3,252}=133.6, p<0.0001\right)$. Means followed by same letter within a panel are not significantly different according to the Ryan-Einot-Gabriel-Welsch Q multiple range test at 5\% probability.

Adults of the two bothriderid beetle species that emerged from the mahogany logs were also caught in the treatment traps, i.e., 18 adults (sexes combined) of $S$. cf. cursorius and 22 adults of $S$. squirei. Adult $S$. cf. cursorius were significantly more attracted to the MSV + ethanol compared to other treatments (Figure 5), whereas adult S. squirei were 
attracted in significant numbers to the MSV + ethanol than to ethanol alone and the control, but the combination did not differ statistically from MSV alone (Figure 5).

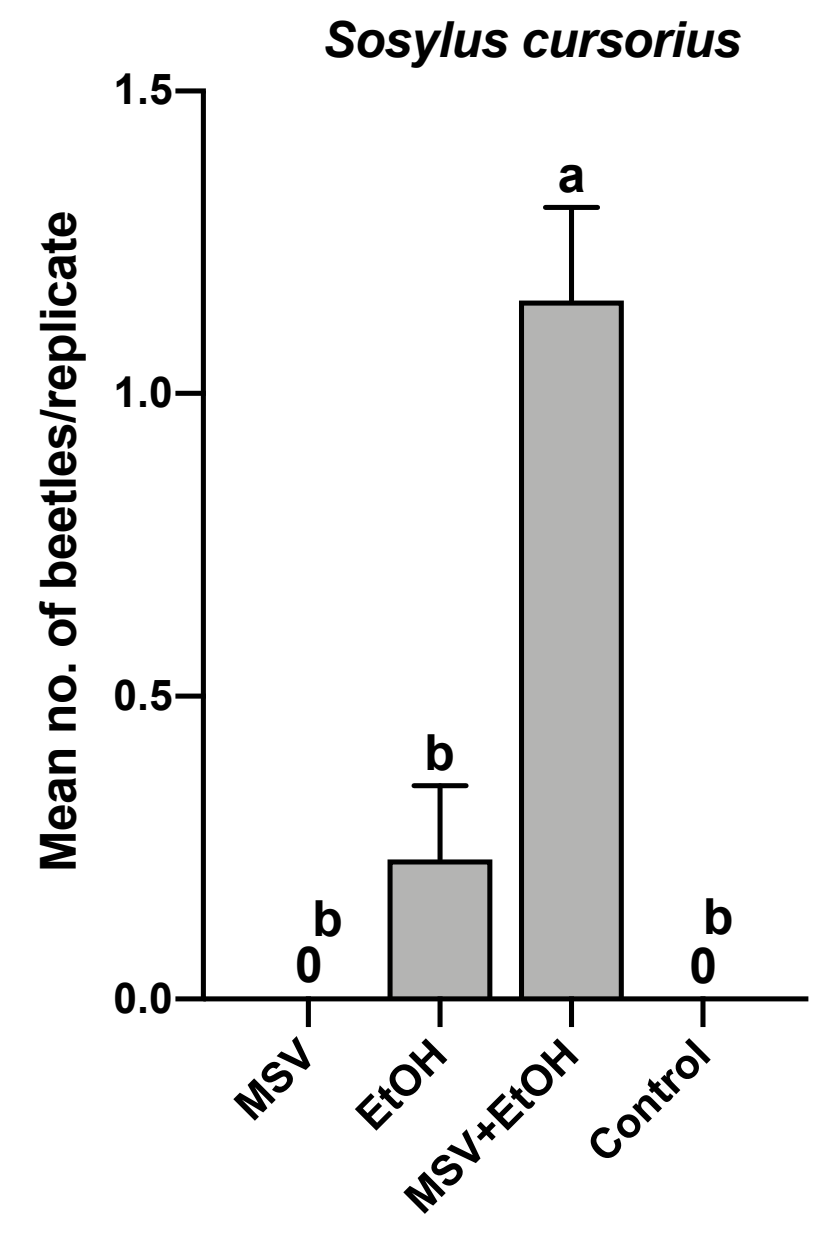

\section{Sosylus squirei}

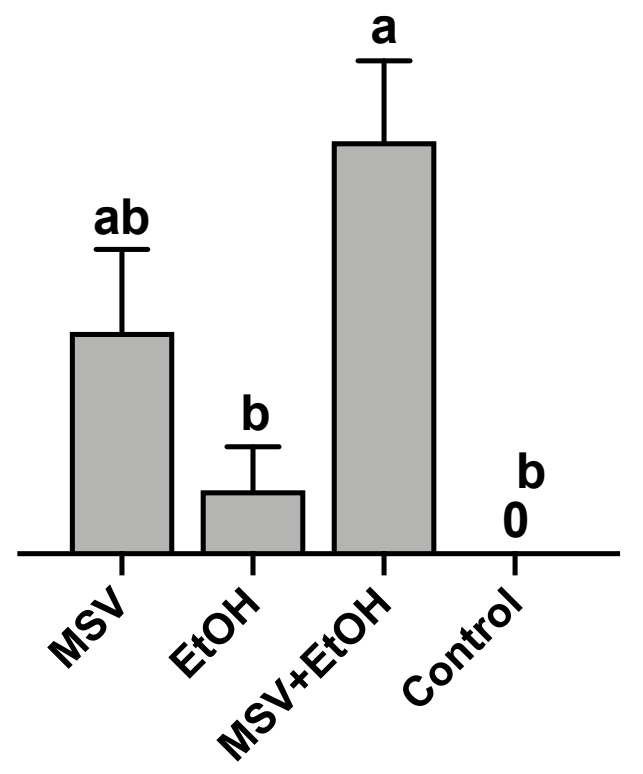

Treatment

Figure 5. Mean $( \pm \mathrm{SE})$ numbers of adults of Sosylus cf. cursorius and Sosylus squirei captured with traps containing synthetic male-specific volatile compounds of Euplatypus parallelus, in combination or not with ethanol. Treatment abbreviations: MSV = male-specific volatiles of E. parallelus, i.e., blend of 3-methyl-1-butanol, 1-hexanol, hexyl acetate, 1-octanol, and geraniol in the same ratio produced by conspecific males; $\mathrm{EtOH}=99.5 \%$ ethanol; control = neat isopropanol. Type of attractant lure significantly affected the trap catch of $S$. cf. cursorius $\left(Q_{3,52}=36.1, p<0.0001\right)$ and $S$. squirei $\left(Q_{3,76}=22.3\right.$, $p<0.0001)$. Means followed by same letter within a panel are not significantly different according to the Ryan-Einot-GabrielWelsch Q multiple range test at 5\% probability.

\section{Discussion}

Adult male E. parallelus produced five sex-specific volatile compounds, including 1-hexanol and smaller amounts of 3-methyl-1-butanol, hexyl acetate, 1-octanol, and transgeraniol. Some of these compounds have been reported as male-produced pheromone components in other platypodine species, e.g., 1-hexanol and 3-methyl-1-butanol in M. flavicornis [25], 1-hexanol in P. cylindrus [26], and trans-geraniol in P. koryoensis [27].

During the field bioassay, traps containing the synthetic blend of male-produced volatile compounds did not attract adult female E. parallelus, equivalent to the catch of traps baited with ethanol or isopropanol (a negative control). Significantly more females were caught in traps baited with the male-specific volatiles + ethanol. Males were not attracted to the male-specific volatiles alone, but they were significantly attracted to ethanol alone. The catch of males did not increase in traps containing ethanol combined with the male-specific volatiles. These results suggest that the male-specific volatiles comprise the 
putative sex-pheromone components of E. parallelus that attract conspecific females, but this attraction functions only in the presence of ethanol that is presumably produced by trees that have been compromised by environmental stress factors. Synergism implies that the response of insects to the mixture of pheromone and plant volatiles is greater than the sum of the responses to the individual components [41]. This phenomenon has been well documented in Lepidoptera for sex pheromones and in Coleoptera (Curculionidae) for aggregation pheromones [41]. Synergism between insect-produced volatile pheromones and host-produced ethanol is a common feature of the life history of several ambrosia beetle species that colonize stressed trees [42].

Stressed trees attract ambrosia beetles because they release large amounts of ethanol in contrast to healthy trees $[18,20]$. Ethanol release reflects the suitability of the host for cultivation of fungal symbionts for feeding the beetles' larvae [21,22]. Trees can be stressed by a range of biotic and abiotic factors, including attack by other insects, phytopathogens, storms, fire, drought, flooding, and forestry practices that injure woody tissues and induce metabolic production of ethanol $[18,20]$. In smaller amounts, ethanol can also be released by fungal fermentation of infected woody tissues $[22,43,44]$.

The putative male-produced sex pheromone combined with ethanol is a critical component in the reproductive behavior of E. parallelus. Ethanol is a kairomone that lures adult males to a suitable host tree, in which they initiate galleries and emit a sex pheromone to call in females. Ethanol combined with the sex pheromone guides conspecific females to the host tree for mating and reproduction. This scenario seems to be true for other platypodine species, where adult males are responsible for seeking suitable host trees and subsequently produce attractant pheromones [5].

The sex ratio of adult $E$. parallelus attracted by the blend of male-specific volatiles + ethanol was male-biased, whereas the sex ratio of conspecifics emerged from mahogany logs was 1:1. However, further independent sampling of the actual sex ratio in the mahogany plantation during the course of bioassays should be undertaken to determine whether males are more attracted to this blend than are females.

In addition to these biological data, we found that the peak in emission of the major male-produced volatile compound (1-hexanol) of E. parallelus lasts from early afternoon until sunset, which corresponds to the period of greatest emergence of conspecific adults. This diurnal activity rhythm appears to occur in other platypodines-for example, $M$. mutatus [24], M. flavicornis [45], and P. quercivorus [46].

During the field trial, adults of S. cf. cursorius and S. squirei were attracted to some treatments. These species belong to the coleopteran family Bothrideridae, subfamily Bothriderinae, tribe Deretraphrini $[47,48]$. Adults of both species were attracted mainly to traps containing the male-specific volatiles of E. parallelus + ethanol. Adults of these species were also recovered from the African mahogany logs evaluated. Based on these results, S. cf. cursorius and S. squirei can be considered potential natural enemies of E. parallelus, which agrees with previous studies that report other species of the genus as predators and ectoparasitoids of platypodine beetles [49-51]. Adult bothriderids may be eavesdropping on the semiochemical channels of E. parallelus to locate their prey.

The increasing global trade of goods and movement of people have contributed to the spread of non-native and invasive insect species, especially forest pests [52]. Semiochemicalbased traps have become important for early detection and monitoring of these invaders wherever they occur [30]. The inexpensive, readily available attractant semiochemicals identified here have good potential for use in surveillance programs of E. parallelus. Lures containing the male-specific volatile compounds of E. parallelus + ethanol could be incorporated into traps for early detection of this species in ports of entry, as well as for delineation of geographical spread and for monitoring in cultivated forests. Moreover, semiochemicalbased attractant lures could be deployed in forest plantations to attract female beetles to kill stations (mass trapping), to nonhost (decoy) tree species, as a mating disruptor, or to recruit natural enemies for biological control of this important platypodine species. 
We have not determined if all five volatile compounds isolated from male E. parallelus are necessary for attraction of females. Furthermore, other volatile organic compounds emitted by suitable host trees, which may enhance the attraction of adult beetles to ethanol, and the optimal release rate of compounds in the lures merit further investigation.

\section{Conclusions}

Adult male E. parallelus sex-specifically produced 1-hexanol (major), 3-methyl-1butanol, hexyl acetate, 1-octanol, and trans-geraniol. In the field, a synthetic blend of these volatile compounds, in combination with ethanol, attracted conspecific females. Males were attracted equally to ethanol alone or to male-specific volatiles + ethanol. It is unclear if all the blend compounds are necessary and sufficient for the attraction that we observed. Two potential natural enemies of E. parallelus were attracted by the combination male-specific volatiles + ethanol blend. Traps containing this semiochemical-based attractant may be useful in surveillance and management programs for this important platypodine species.

Supplementary Materials: The following are available online at https://www.mdpi.com/2073-4 395/11/2/266/s1, Figure S1: African mahogany, Khaya senegalensis trees showing the symptoms of dieback wilt syndrome (a) and resinosis (b) supposedly attributed to stress factors in a plantation in southwestern Brazil.

Author Contributions: H.L.R., W.D.S., and J.M.S.B. conceived the study; H.L.R. and W.D.S. obtained the volatile extracts and identified the pheromone candidates; H.L.R. carried out the field bioassays and identified the collected specimens; W.D.S. performed the statistical analyses; H.L.R. wrote the manuscript draft; J.M.S.B. and W.D.S. revised and edited the manuscript draft; J.M.S.B. supervised the research and obtained the funding. All authors have read and agreed to the published version of the manuscript.

Funding: This research was funded by INCT-Semioquímicos na Agricultura (FAPESP, grant \#2014/ 50871-0; CNPq, grant \#465511/2014-7) and Coordenação de Aperfeiçoamento de Pessoal de Nível Superior (CAPES, grant \#001).

Acknowledgments: We would like to thank Terence Groot and his family for supplying the biological material and for allowing us access to the African mahogany plantation in Inocência. We thank Sérgio R. Rodrigues (UEMS, Brazil) and Arodí P. Favaris (USP/ESALQ, Brazil) for their technical support, and Nathan P. Lord (Louisiana State University, USA) for essential information on the taxonomy of the fascinating beetle family Bothrideridae. Our special thanks to Stephen Lapointe for reviewing the manuscript and to Leonardo F. Santos for his contribution to the trap design.

Conflicts of Interest: The authors declare no conflict of interest.

\section{References}

1. Wood, S.L.; Bright, D.R. A Catalog of Scolytidae and Platypodidae (Coleoptera), Part 2: Taxonomic Index Volume B; Brigham Young University: Provo, UT, USA, 1992; Volume 13, pp. 1084-1241.

2. Beaver, R.A. The invasive neotropical ambrosia beetle Euplatypus parallelus (Fabricius, 1801) in the oriental region and its pest status (Coleoptera: Curculionidae, Platypodinae). Entomol. Mon. Mag. 2013, 149, 143-154.

3. Gümüs, E.M.; Ergün, A. Report of a pest risk analysis for Platypus parallelus (Fabricius, 1801) for Turkey. EPPO Bull. 2015, 45, 112-118. [CrossRef]

4. Schedl, K.E. Scolytidae und Platypodidae Afrikas III, Familie Platypodidae. Revista Entomol. Moçamb. 1962, 5, 595-1352.

5. Kirkendall, L.R.; Biedermann, P.H.W.; Jordal, B.H. Evolution and diversity of bark and ambrosia beetles. In Bark Beetles: Biology and Ecology of Native and Invasive Species; Vega, F.E., Hofstetter, R.W., Eds.; Academic Press: Cambridge, UK, 2015 ; pp. 85-156.

6. Ribeiro, A.; Ferraz Filho, A.C.; Oliveira, E.B. Usos, importância econômica e perspectivas de mercado. In Mogno-Africano (Khaya spp.): Atualidades e Perspectivas do Cultivo no Brasil; Reis, C.A.F., Oliveira, E.B., Santos, A.M., Eds.; Embrapa: Brasília, Brazil, 2019; pp. 50-73. Available online: http://ainfo.cnptia.embrapa.br/digital/bitstream/item/202696/1/Mogno-Africano-08-10-2019.pdf (accessed on 19 January 2021).

7. Sanderson, F.R.; Fong, Y.K.; Pheng, Y.C.; Ong, K.H.; Anuar, S. A fusarium wilt (Fusarium oxysporum) of angsana (Pterocarpus indicus) in Singapore. I, Epidemiology and identification of the causal organism. Arboric. J. 1997, 21, 187-204. [CrossRef]

8. Philip, E. Wilt disease of angsana (Pterocarpus indicus) in Peninsular Malaysia and its possible control. J. Trop. For. Sci. 1999, 11, 519-527. Available online: https:/ / www.jstor.org/stable/43582560 (accessed on 19 January 2021). 
9. Kirkendall, L.R.; Islam, M.R. Widespread wilting of Dalbergia sissoo in Bangladesh: The role of timber borers. In Mortality of Sissoo (Dalbergia sissoo) and Top Dying of Sundri (Heritiera Fomes) in Bangladesh; Baksha, M.W., Ed.; Bangladesh Forest Research Institute: Chittagong, Bangladesh, 2003; pp. 34-38.

10. Zanuncio, J.C.; Sossai, M.F.; Couto, L.; Pinto, R. Occurrence of Euplatypus parallelus, Euplatypus sp. (Col.: Euplatypodidae) and Xyleborus affinis (Col.: Scolytidae) in Pinus sp. in Ribas do Rio Pardo, Mato Grosso do Sul, Brazil. Rev. Árvore 2002, 26, 387-389. [CrossRef]

11. Zanuncio, J.C.; Sossai, M.F.; Flechtmann, C.A.H.; Zanuncio, T.V.; Guimarães, E.M.; Espindula, M.C. Plants of an Eucalyptus clone damaged by Scolytidae and Platypodidae (Coleoptera). Pesqui. Agropecuária Bras. 2005, 40, 513-515. [CrossRef]

12. Bumrungsri, S.; Beaver, R.A.; Phongpaichit, S.; Sittichaya, W. The infestation by an exotic ambrosia beetle, Euplatypus parallelus (F.) (Coleoptera: Curculionidae: Platypodinae) of Angsana trees (Pterocarpus indicus Willd.) in southern Thailand. Songklanakarin J. Sci. Technol. 2008, 30, 579-582. Available online: https://rdo.psu.ac.th/sjstweb/journal/30-5/0125-3395-30-5-579-582.pdf (accessed on 19 January 2021).

13. Maruthadurai, R.; Desai, A.R.; Singh, N.P. First record of ambrosia beetle (Euplatypus parallelus) infestation on cashew from Goa, India. Phytoparasitica 2014, 42, 57-59. [CrossRef]

14. Hiremath, S.R.; Prathapan, K.D. First report of the invasive South American pinhole borer, Euplatypus parallelus (Fabricius) (Coleoptera: Curculionidae: Platypodinae), on rubber in India. Coleopt. Bull. 2019, 73, 714-717. [CrossRef]

15. Rainho, H.L.; Flechtmann, C.A.H.; Silva, H.A.S.; Rocha, E.T.A. Ataque de Scolytinae e Platypodinae (Curculionidae) em seringueiras (Hevea brasiliensis) em São Paulo. In Proceedings of the 10th Congresso de Ecologia do Brasil, São Lourenço, Brazil, 16-22 September 2011; Abstract 1101. pp. 1-2. Available online: http://seb-ecologia.org.br/revistas/indexar/anais/xceb/ resumos/1101.pdf (accessed on 19 January 2021).

16. Elliott, H.J.; Madden, J.L.; Bashford, R. The association of ethanol in the attack behaviour of the mountain pinhole borer Platypus subgranosus Schedl (Coleoptera: Curculionidae: Platypodinae). J. Aus. Entomol. Soc. 1983, 22, 299-302. [CrossRef]

17. Shore, T.L.; McLean, J.A. Attraction of Platypus wilsoni Swaine (Coleoptera: Platipodidae) to traps baited with sulcatol, ethanol and alpha-pinene. Can. For. Serv. Res. Notes 1983, 3, 24-25.

18. Kimmerer, T.W.; Kozlowski, T.T. Ethylene, ethane, acetaldehyde, and ethanol production by plants under stress. Plant Physiol. 1982, 69, 840-847. [CrossRef] [PubMed]

19. Ranger, C.M.; Reding, M.E.; Schultz, P.B.; Oliver, J.B. Influence of flood-stress on ambrosia beetle host-selection and implications for their management in a changing climate. Agric. For. Entomol. 2013, 15, 56-64. [CrossRef]

20. Kelsey, R.G.; Gallego, D.; Sánchez-García, F.J.; Pajares, J.A. Ethanol accumulation during severe drought may signal tree vulnerability to detection and attack by bark beetles. Can. J. For. Res. 2014, 44, 554-561. [CrossRef]

21. Klimetzek, D.; Köhler, J.; Vité, J.P.; Kohnle, U. Dosage response to ethanol mediates host selection by secondary bark beetles. Naturwissenschaften 1986, 73, 270-272. [CrossRef]

22. Ranger, C.M.; Biedermann, P.H.W.; Phuntumart, V.; Beligala, G.U.; Ghosh, S.; Palmquist, D.E.; Mueller, R.; Barnett, J.; Schultz, P.B.; Reding, M.E.; et al. Symbiont selection via alcohol benefits fungus farming by ambrosia beetles. Proc. Natl. Acad. Sci. USA 2018, 115, 4447-4452. [CrossRef]

23. Gonzalez-Audino, P.; Villaverde, R.; Alfaro, R.; Zerba, E. Identification of volatile emissions from Platypus mutatus (=sulcatus) (Coleoptera: Platypodidae) and their behavioral activity. J. Econ. Entomol. 2005, 98, 1506-1509. [CrossRef]

24. Gatti Liguori, P.; Zerba, E.; Alzogaray, R.A.; Gonzalez-Audino, P. 3-Pentanol: A new attractant present in volatile emissions from the ambrosia beetle, Megaplatypus mutatus. J. Chem. Ecol. 2008, 34, 1446-1451. [CrossRef]

25. Renwick, J.A.A.; Vité, J.P.; Billings, R.F. Aggregation pheromones in the ambrosia beetle Platypus flavicornis. Naturwissenschaften 1977, 64, 226. [CrossRef]

26. Algarvio, R.; Teixeira, C.; Barata, E.; Pickett, J.; Casas Novas, P.; Figueiredo, D. Identification of a putative aggregation pheromone from males Platypus cylindrus (Coleoptera: Platypodidae). In Proceedings of the 19th ISCE Annual Meeting, Hamburg, Germany, 3-7 August 2002; p. 152. Available online: https:/ / www.chemecol.org/programs/2002.pdf (accessed on 19 January 2021).

27. Kim, J.; Lee, S.G.; Shin, S.C.; Kwon, Y.D.; Park, I.K. Male-produced aggregation pheromone blend in Platypus koryoensis. J. Agric. Food Chem. 2009, 57, 1406-1412. [CrossRef] [PubMed]

28. Tokoro, M.; Kobayashi, M.; Saito, S.; Kinuura, H.; Nakashima, T.; Shoda-Kagaya, E.; Kashiwagi, T.; Tebayashi, S.; Kim, C.; Mori, K. Novel aggregation pheromone, (1S,4R)-p-menth-2-en-1-ol, of the ambrosia beetle, Platypus quercivorus (Coleoptera: Platypodidae). Bull. FFPRI 2007, 6, 49-57. Available online: https:/ / www.ffpri.affrc.go.jp/labs/kanko/402-5.pdf (accessed on 19 January 2021).

29. Gerónimo-Torres, J.D.C.; Pérez-De La Cruz, M.; De La Cruz-Pérez, A.; Torres-De La Cruz, M. Scolytinae y Platypodinae (Coleoptera: Curculionidae) asociados a manglares de Tabasco, México. Rev. Colomb. Entomol. 2015, 41, 257-261. Available online: http: / / www.scielo.org.co/scielo.php?script=sci_arttext\&pid=S0120-04882015000200018\&lng=en\&nrm=iso (accessed on 19 January 2021).

30. Poland, T.M.; Rassati, D. Improved biosecurity surveillance of non-native forest insects: A review of current methods. J. Pest Sci. 2019, 92, 37-49. [CrossRef]

31. Thube, S.H.; Mohan, C.; Pandian, R.T.P.; Saneera, E.K.; Sannagoudra, H.M.; Hedge, V.; Chowdappa, P. First record of the invasive Neotropical ambrosia beetle Euplatypus parallelus (Fabricius, 1801) (Coleoptera: Curculionidae: Platypodinae) infesting arecanut in Karnataka, India. Coleopt. Bull. 2018, 72, 713-716. [CrossRef] 
32. Gonzalez-Audino, P.; Gatti Liguori, P.; Zerba, E. Translucent pheromone traps increase trapping efficiency of ambrosia beetle Megaplatypus mutatus. Crop. Prot. 2011, 30, 745-747. [CrossRef]

33. Funes, H.; Zerba, E.; Gonzalez-Audino, P. Comparison of three types of traps baited with sexual pheromones for ambrosia beetle Megaplatypus mutatus (Coleoptera: Platypodinae) in poplar plantations. J. Econ. Entomol. 2009, 102, 1546-1550. [CrossRef]

34. Funes, H.; Zerba, E.; Gonzalez-Audino, P. Effect of release rate and enantiomeric composition response to pheromones of Megaplatypus mutatus (Chapuis) in poplar plantations of Argentina and Italy. Bull. Entomol. Res. 2013, 103, 564-569. [CrossRef]

35. Gallego, D.; Galián, J.; Diez, J.J.; Pajares, J.A. Kairomonal responses of Tomicus destruens (Col., Scolytidae) to host volatiles $\alpha$-pinene and ethanol. J. Appl. Entomol. 2008, 132, 654-662. [CrossRef]

36. Wong, J.C.H.; Meier, L.R.; Zou, Y.; Mongold-Diers, J.A.; Hanks, L.M. Evaluation of methods used in testing attraction of cerambycid beetles to pheromone-baited traps. J. Econ. Entomol. 2017, 110, 2269-2274. [CrossRef]

37. SAS Institute. SAS/STAT V.9.3 User's Guide; SAS Institute: Cary, NC, USA, 2011.

38. Sokal, R.R.; Rohlf, F.J. Biometry, 3rd ed.; W.H. Freeman: New York, NY, USA, 1995.

39. Quinn, G.P.; Keough, M.J. Experimental Design and Data Analysis for Biologists; Cambridge University Press: Cambridge, UK, 2002. [CrossRef]

40. Newcombe, R.G. Two-sided confidence intervals for the single proportion: Comparison of seven methods. Stat. Med. 1998, 17, 857-872. [CrossRef]

41. Reddy, G.V.P.; Guerrero, A. Interactions of insect pheromones and plant semiochemicals. Trends Plant Sci. 2004, 9, $253-261$. [CrossRef] [PubMed]

42. Byers, J.A. Host-tree chemistry affecting colonization in bark beetles. In Chemical Ecology of Insects 2; Cardé, R.T., Bell, W.J., Eds.; Chapman \& Hall: New York, NY, USA, 1995; pp. 154-213. [CrossRef]

43. Graham, K. Anaerobic induction of primary chemical attractancy for ambrosia beetles. Can. J. Zool. 1968, 46, 905-908. [CrossRef]

44. Moeck, H.A. Ethanol as the primary attractant for the ambrosia beetle Trypodendron lineatum (Coleoptera: Scolytidae). Can. Entomol. 1970, 102, 985-995. [CrossRef]

45. Madrid, F.; Vité, J.P.; Renwick, J.A.A. Evidence of aggregation pheromones in the ambrosia beetle Platypus flavicornis (F.). Z. Angew. Entomol. 1972, 72, 73-79. [CrossRef]

46. Nam, Y.; Choi, W.I. Diurnal flight pattern of Platypus koryoensis (Coleoptera: Platypodinae) in relation to abiotic factors in Korea. J. Asia Pac. Entomol. 2014, 17, 417-422. [CrossRef]

47. Pascoe, F.P. List of the Colydiidae collected in the Amazons valley by H.W. Bates, Esq., and descriptions of new species by Francis P. Pascoe. J. Entomol. 1863, 2, 79-99.

48. Slipinski, A.; Lord, N.P.; Lawrence, J.F. Bothrideridae Erichson, 1845. In Handbook of Zoology. Arthropoda: Insecta: Coleoptera. Volume 3: Morphology and Systematics (Phytophaga); Leschen, R.A.B., Beutel, R.G., Eds.; De Gruyter: Berlin, Germany, 2014; pp. 411-422. [CrossRef]

49. Browne, F.G. Sosylus spectabilis Grouvelle (Coleoptera, Colydiidae), a predator and parasite of African ambrosia beetles. In 5th Report West African Timber Borer Research Unit 1961-1962; Crown Agents: London, UK, 1962; pp. 91-96.

50. Roberts, H. A note on the Nigerian species of the genus Sosylus Erichson (Col. Colydiidae), parasites and predators of ambrosia beetles. J. Nat. Hist. 1969, 3, 85-91. [CrossRef]

51. Roberts, H. Description of the developmental stages of Sosylus spp. (Coleoptera: Colydiidae) from New Guinea, parasites and predators of ambrosia beetles (Coleoptera: Platypodidae). Bull. Entomol. Res. 1980, 70, 245-252. [CrossRef]

52. Meurisse, N.; Rassati, D.; Hurley, B.P.; Brockerhoff, E.G.; Haack, R.A. Common pathways by which non-native forest insects move internationally and domestically. J. Pest Sci. 2019, 92, 13-27. [CrossRef] 